\title{
Culturas juvenis e temas sensíveis ao contemporâneo: uma entrevista com Carles Feixa Pampols
}

\section{Juvenile cultures and themes sensitive to the contemporary: an interview with Carles Feixa Pampols}

\author{
Victor Hugo Nedel Oliveira* \\ Miriam Pires Corrêa de Lacerda** \\ Andreia Mendes dos Santos*** \\ Carles Feixa Pampols ${ }^{* * * *}$
}

\begin{abstract}
RESUMO
Carles Feixa Pampols é professor catedrático de antropologia social da Universidade Pompeu Fabra, em Barcelona. É doutor em Antropologia Social pela Universidade de Barcelona e Doutor Honoris Causa pela Universidade de Manizales (Colômbia). O Dr. Feixa tem se dedicado aos estudos das Culturas Juvenis, tendo publicado mais de 50 livros sobre o tema e sendo pesquisador visitante em importantes universidades de países como: Espanha, Itália, México, França, Argentina, Chile, Colômbia, Estados Unidos, Peru, Brasil, entre outros. Nesta entrevista, concedida aos professores Victor Oliveira, Miriam Lacerda e Andreia dos Santos, o professor Feixa discute temas importantes para o campo de pesquisa na área de juventudes, bem como apresenta pistas para as opções metodológicas no campo. Ele afirma, dentre suas contribuições, que uma maneira interessante de estudar as juventudes é pelo viés das histórias de vida, pois se considera que a juventude não tem

* Universidade Federal do Rio Grande do Sul. Porto Alegre, Rio Grande do Sul, Brasil. E-mail: victornedel@hotmail.com. https://orcid.org/0000-0001-5624-8476.

** Universidade Feevale. Novo Hamburgo, Rio Grande do Sul, Brasil. E-mail: miriamlacerda@feevale.br. https://orcid.org/0000-0003-0892-1149.

*** Pontifícia Universidade Católica do Rio Grande do Sul. Porto Alegre, Rio Grande do Sul, Brasil. E-mail: andreia.mendes@pucrs.br. https://orcid.org/0000-0001-7013-0239.

**** Universitat Pompeo Fabra. Barcelona, Espanha. E-mail: carlesfeixa@gmail.com. https://orcid.org/0000-0002-4874-1604.
\end{abstract}


história de vida ou biografia, porque ainda estaria em construção. Por outro lado, acredita ser justamente nesta fase no qual poderiam começar a narrar e construir suas histórias, assim, as utiliza para a construção de suas pesquisas.

Palavras-chave: Juventudes. Coletividade. Educação.

\begin{abstract}
Carles Feixa Pampols is a professor of social anthropology at Pompeu Fabra University in Barcelona. He holds a $\mathrm{PhD}$ in Social Anthropology from the University of Barcelona and the title of Doctor Honoris Causa from the University of Manizales (Colombia). Dr. Feixa has been dedicated to the studies of Youth Cultures, having published more than 30 books on the subject and being a visiting researcher in important universities in countries like Spain, Italy, Mexico, France, Argentina, Chile, Colombia, United States, Peru and Brazil, among others. In this interview, given to teachers Victor, Miriam and Andreia, Professor Feixa discusses important themes for the field of research in the area of youth, and presents clues for the methodological options in this field. He affirms, based on his rich contributions, that an interesting way of studying youth is by the bias of life stories. It is considered that youth has no life story or biography, as it would still be under construction; however, he believes that it is precisely the moment in which they could begin to narrate and construct their stories, and thus, uses them for the construction of his research.
\end{abstract}

Keywords: Youths. Collective. Education.

\title{
Apresentação
}

Carles Feixa Pampols é um dos mais importantes pesquisadores das Juventudes na atualidade. Desde o início de seu interesse pela pesquisa no campo das Juventudes já publicou uma série de obras que se tornaram referências mundiais para os estudiosos do campo.

No primeiro mês do ano de 2018, na cidade de Belo Horizonte, na Faculdade Jesuíta (FAJE), realizou-se o II Simpósio Nacional “Aproximações com o Mundo Juvenil", evento este no qual o Professor Feixa foi convidado para a conferência de abertura, intitulada "Juventudes e Ações Coletivas Contemporâneas". Após relevantes estudos sobre a obra do Professor Feixa, e, levando em conta a oportunidade única de conhecê-lo e dialogar com o renomado pesquisador sobre o campo das juventudes, os professores entrevistadores solicitaram, na 
oportunidade, uma entrevista com o Professor Feixa que, muito prontamente, aceitou o convite.

Nesta entrevista, realizada em Belo Horizonte, aos vinte e cinco dias do mês de janeiro do ano de 2018, são apresentadas sínteses analíticas desenvolvidas pelo Professor Carles Feixa, decorrentes de sua ampla pesquisa e experiência no campo das juventudes e culturas juvenis. Sínteses analíticas estas as quais temos a honra de compartilhar com os colegas pesquisadores e interessados no campo.

\section{Entrevistadores: A partir de seus estudos na área das Juventudes, quais seriam as reivindicações mais atuais destes sujeitos?}

Carles Feixa: Digamos que em 2018, onde nos encontramos, e sendo um dia simbolicamente interessante, como comentei esta manhã na mesa redonda, hoje é o sétimo aniversário da ocupação da Praça de Tahrir, no Cairo, em mãos de movimentos juvenis do Egito, que foi o ponto de partida da Primavera Árabe, depois disso ocorreram os movimentos indignados de "Occupy", em escala global. Sete anos depois, no Egito, a situação não é otimista e, internacionalmente, a respeito da juventude tão pouco, sem dúvidas. Indo a tua pergunta, esses movimentos serviram como ponto de inflexão sobre uma visão da juventude que poderíamos denominar esquizofrênica, no âmbito internacional, visto que, por uma parte, nunca como agora a juventude havia sido tão idealizada, tão imitada, havia tido tanto prestígio simbólico, no sentido de que todos querem ser jovens, todos querem vestir-se como jovens, ouvir as músicas as quais os jovens gostam, ter um corpo jovem e ter, em especial, a habilidade tecnológica que os jovens possuem para conectarem-se com o mundo digital. Portanto, nunca como agora a juventude havia sido a vanguardista das mudanças tecnológicas, estéticas e econômicas, porque também as novas formas de dominação econômica da sociedade em rede respondem a este modelo flexível e esta capacidade da juventude de aprender constantemente. Por outro lado, e esta é a contradição de meu ponto de vista, nunca como agora as juventudes vêm sendo tão excluídas, tão marginalizadas, tão violentadas em todos os sentidos e estão sendo afugentadas de qualquer tipo de poder econômico ou político. A ponto de alguns autores falarem de "juvenicídio moral" da juventude, não apenas o juvenicídio físico ou a eliminação física dos jovens dissidentes - algo que se reproduz cotidianamente com algumas minorias étnicas ou raciais em países latino-americanos -, mas sobretudo o chamado juvenicídio moral, que seria a estigmatização, o menosprezo constante, o não levar em conta o que os jovens querem ou dizem. E quais seriam as demandas das juventudes contemporâneas senão basicamente - não há uma demanda que sirva para todas as juventudes, mas eu diria alguns princípios comuns: o principal seria ter voz - a capacidade de serem escutados. Mais do que ter voz, pois já a têm e a utilizam, por vezes 
de maneira estridente, seus desejos de serem ouvidos, o fato de que expressam através da arte ou da música ou até mesmo através da mesma violência que não deixa de ser um elemento para ser escutado, ou seja, ser lido ou ser escutado pelos adultos, pela sociedade em geral. Este seria o elemento básico. O segundo seria um melhor acesso ao trabalho ao longo de suas vidas, posto que a juventude sempre havia tido uma preparação para o mercado de trabalho, os jovens tinham possibilidades de acesso a alguma ocupação remunerada. Isto a médio ou longo prazo levava a uma possibilidade de emanciparem-se e ter uma carreira autoconstruída. Isto está desaparecendo, está se precarizando de uma maneira alarmante. $\mathrm{O}$ trabalho dos jovens: o salário, o tempo e as condições de trabalho, eles estão perdendo direitos sociais que historicamente haviam sido conquistados na modernidade. $\mathrm{O}$ acesso a um modo de sustento, de ganhar a vida, seria eu creio uma das demandas, senão uma das alternativas é depender da família ou do Estado, que sempre supõe um corte no processo de emancipação. E em terceiro lugar, como demanda universal, seria um acesso igualitário à informação, portanto, às redes sociais e ao mundo digital. Inclusive, nos lugares mais afastados do Brasil, por exemplo, que não tenha algum jovem, hoje em dia, que não saiba o que é um celular ou o que é internet ou tenha algum acesso às redes sociais. $\mathrm{O}$ capitalismo tardio gerou muitas desigualdades no acesso às redes e hoje poderíamos dizer que ao contrário da reivindicação ao alfabetismo universal - reivindicação básica do século XIX -, no século XXI, o alfabetismo digital seria um dos desafios a ser superado.

\section{Entrevistadores: Em seu contexto local (Barcelona) como o senhor} avalia a participação dos jovens no movimento político recém vivenciado na Catalunha?

Carles Feixa: Esta é uma temática de pesquisa que precisamente deveria ser tratada por pesquisadores que não sejam nem catalães nem espanhóis, porque se trata de uma "batata quente" ou uma zona de risco. Quando o pesquisador está no meio da situação, não se tem capacidade de fazer uma análise imparcial. Porém o que posso comentar é que a independência da Catalunha, que está ainda em processo, teve um protagonismo juvenil significativo e não descartável. Tanto que as novas gerações nasceram depois da transição democrática de 1978, quando se aprovou a constituição atual vigente na Espanha. Portanto, já se passaram 40 anos e as pessoas de menos de 40 anos, ou seja, a juventude adulta, nasceram depois da constituição. E o que se diz na Espanha, por parte do governo espanhol, é que esta constituição é imutável ou imodificável, tendo sido aprovada não há nada mais o que fazer. Os jovens, não somente os catalães, mas também os jovens espanhóis em geral não entendem, ou seja, "por que temos que aceitar ao pé da letra o que se votou há 40 anos e que nós não votamos". Eu mesmo, 
eu tinha 15 anos. Entendo que essa constituição tinha o objetivo de fechar as feridas da ditadura e da guerra civil espanhola que nunca haviam se fechado. Aparentemente se fecharam, mas na realidade não, porque não se reconheceu o mal que se produziu; a herança da guerra civil libertou o que aconteceu após a própria guerra: perseguição e mortes, e enquanto ao tema nacional: a redistribuição territorial da Espanha. Nós, catalães pensamos que a Espanha é uma nação de nações, assim a denominamos. Não é um estado unitário, centralizado, que cuida de governar, como a França, um único país com um estado-nação sem diferenças; a Espanha foi, desde sua constituição, sua origem, integradora de diferentes nações. Também Portugal era uma das nações da Espanha romana e da Espanha medieval: Catalunha, Euskadi, País Basco, Galícia e Castilha, que seria a nação dominante na história da Espanha. Nos últimos anos houve uma tentativa de recentralização que em 1978, com a constituição, mais ou menos se chegou a um acordo de autonomias que havia de afetar estas quatro nações autônomas, o que depois se generalizou para todas as comunidades espanholas. A partir de 2010, quando há um acesso ao Tribunal constitucional de autonomia catalã, quando começa todo esse processo de independência que, no caso da juventude, se vê por uma parte como a incompreensão de ter que assumir ao pé da letra o que foi a constituição espanhola. Como exemplo, cito o sistema monárquico que nunca se votou, e dado que são gerações juvenis que foram educadas na democracia, não se sentem com a necessidade de vincularem-se a este compromisso histórico que se deu em 1978. Com o qual, a maioria dos jovens optou por participar neste processo de independência, no qual alguns grupos como a Candidatura de Unidade Popular (CUP) foram muito ativos. Ainda que também não se possa descartar uma tendência da juventude neoconservadora, que estava adormecida e acordou-se contrariamente aos independentistas, a qual se identificou com a Espanha em um novo nacionalismo espanhol que não estava desaparecido, mas oculto ou subterrâneo. De modo que nos últimos momentos, nos últimos meses, por exemplo, no referendo de outubro passado, significativamente quem organizou o referendo foram os jovens através dos chamados CDR - Comitês de Defesa da República. Quando este referendo foi proibido pelo Estado espanhol e o governo catalão não podia organizá-lo porque estava sob o risco de ser condenado por isso, de algum modo delegou-se a organização a estes comitês e boa parte dos membros eram estudantes e jovens, alguns meus próprios alunos. E como se organizaram? Guardaram em suas casas as urnas e as cédulas eleitorais, comunicaram-se através das redes sociais e fizeram também com que a guarda civil que esteve com mais de dez mil policiais na Catalunha neste período não encontrassem nenhuma urna. Encontraram algumas cédulas e confiscaram, mas não nas casas particulares onde as guardaram, mas numa gráfica. No dia do referendo, pelas oito horas da 
manhã apareceram os jovens em seus carros, tiraram as urnas e organizaram os colégios eleitorais de uma maneira muito simples. O que aconteceu depois foi, por uma parte, um "quero e não posso", uma tentativa de defender este voto e de proclamar a república catalã; por outra parte, os jovens se deram conta de que quem havia assumido a liderança já não eram eles, mas, sim, os políticos tradicionais que não costumam ser jovens. Eles haviam tomado as rédeas do assunto e haviam começado a negociar. Agora a juventude vê este problema como um problema herdado de gerações anteriores que não foram capazes de falar e, dialogando, encontrar uma solução, como em um referendo reconhecido por todas as partes ou uma nova proposta de reorganização política de Espanha que desse um maior poder, neste caso, à Catalunha. Eles que receberam esta "batata envenenada" de gerações anteriores, a única solução que há é a opção pela independência, ou seja, fazer borrão e começar de novo. Isto, obviamente, possui um aspecto positivo e uma tentativa de criar algo novo, a criatividade inclusive de criar um tipo de Estado novo, que não seja um Estado burocrático, centralista, antiquado, por exemplo, um "Estado 2.0" que leve em conta esta juventude que pretende descobrir mediterrâneos não reconhece o poder da experiência, o que necessita um pouco de paciência. E neste impasse estamos: de uma juventude que quer reconstruir não apenas o processo catalão, que é uma metáfora de um processo político que na Espanha o grupo $15 \mathrm{M}$ também trabalhou. Ou seja, o esgotamento da transição democrática e a necessidade de reinventar as estruturas políticas para aproximá-las mais da cidadania que, como no caso catalão, põe-se em manifesto.

\section{Entrevistadores: Que rumos o senhor acredita que tomará a pesquisa} no campo das juventudes, em tempos nos quais as juventudes se tornaram o ideal da cultura?

Carles Feixa: Paradoxalmente, hoje, mais do que nunca, há mais investigadores de juventudes que antes, e mais legitimados, digamos, quando eu comecei isto, no Brasil e na América Latina e em todo o mundo, as juventudes eram temas de investigação social, em sociologia, antropologia e psicologia. Nos congressos em comunicação, nos congressos em disciplinas e as mesas de juventudes eram as mais massivas. Isto, há 30 anos não acontecia, inclusive alguns questionavam se as juventudes eram um tema importante para a pesquisa, em ter tantas cátedras, disciplinas e publicações. Hoje praticamente há uma importante massa crítica em revistas pelo mundo, há livros, publicações, coleções, cursos de especialização, doutorados; há mais investigadores em juventudes do que nunca. Porém, a juventude está perdendo a especificidade como objeto de estudo. Isto posto que os temas de pesquisa em juventudes seja qualquer tema, já que as juventudes se tornam um laboratório para estudar as 
novas tendências sociais e culturais. Então, se torna difícil especificar quais são as linhas de pesquisa dominantes. Ainda que, arriscando-me, eu assinalaria três importantes linhas, sendo as duas primeiras as linhas de pesquisa clássicas, que são os estudos de transição e os estudos de culturas juvenis. Os estudos de transição, por exemplo, com José Machado Pais e outros autores europeus que teorizaram muito bem a transição da infância para a vida adulta e como esta se complica com a modernidade tardia, esta transição linear se transforma em transições descontínuas, as transições escola-trabalho, família de origem - família de destino, mas que não desaparecem, pois seguem sendo uma fase de transição, mas que dura muito tempo, sem ser algo linear, mas que possuem muitos altos e baixos. Em resumo, trata-se de pesquisar as individualizações das transições juvenis, as transições autogestionadas, também tendo em conta as diferenças sociais, de classe, de gênero. Como os problemas seguem sendo profundamente desiguais, por exemplo, quando se referem ao sistema informativo ou ao sistema de trabalho, como se cruzam os estudos de classes, isto é importante. A segunda linha são as culturas juvenis, com a particularidade de que hoje não estamos falando somente de minorias, as chamadas tribos urbanas, as bandas, mas é falar de que as culturas juvenis hoje afetam todas as juventudes, ou seja, os jovens estão vivendo, envolvendo-se e participando de algum tipo de cultura juvenil. A outra particularidade é que não são culturas juvenis em tempo completo, em todo o tempo, não é como ser "hippie", que era quase uma conversão de vida, hoje em dia é quase uma forma de se disfarçar carnavalescamente de uma personalidade que se assume, como algo importante e vital, mas que não dura para sempre. A novidade, a partir da linha de pesquisa em culturas juvenis, é que não afeta apenas as juventudes, mas afeta a outros grupos de idade, que envolve tanto as infâncias como os adultos, os que atuam, participam e atuam como jovens ao longo da vida, ou seja, a juventude é algo mais amplo que o período cronológico. E o terceiro ponto, no âmbito da pesquisa, seria a cultura digital, o envolvimento dos jovens nas novas tecnologias, como toda a sociedade, mas com a particularidade de que a juventude é a pioneira na exploração dos modos de vida digitais, quanto à exploração, à experimentação e ao consumo destes produtos. Este seria o tema dos jovens "prosumidores", que seriam os jovens que consomem tecnologia, consomem mais tempo, mais recursos, mas sobretudo são também produtores de aparelhos tecnológicos, de tecnologias, de recursos, de linguagens e usos não previstos destas tecnologias pelas empresas que as criaram, mas os jovens as apropriam e as utilizam. Como as tecnologias vão se modificando com o uso e como vão se unindo os corpos às máquinas, como vão se convertendo em ciberculturas juvenis, sem ser uma avaliação pejorativa, mas, sim, um dado de realidade que todos temos que levar em conta. 


\section{Entrevistadores: Em "Juvenopédia" o senhor apresenta um mapea- mento das juventudes ibero-americanas. Seria possível estabelecer algumas marcas de proximidades entre as práticas juvenis destes países? Quais seriam suas proximidades e distanciamentos?}

Carles Feixa: O livro Juvenopédia é um projeto que surgiu em colaboração com uma antropóloga peruana, Patrícia Olliart, com quem colaboro nos últimos anos em várias iniciativas e em vários projetos. Patrícia é peruana, mas está radicada em New Castle (Inglaterra). Inicialmente, a origem do livro tratava-se em reunir estudos com um marco teórico e metodológico parecido, escrito por discípulos ou colaboradores de ambos, ou seja, pesquisadores do Chile, da Argentina, da Colômbia, da Espanha e de Portugal, que formam os principais países ibero-americanos que em sintonia estiveram pesquisando as culturas juvenis em seus territórios com parâmetros teórico-metodológicos semelhantes, com base nos estudos culturais, na teoria crítica e nas metodologias qualitativas, como forma de buscar as juventudes, e com as metodologias participativas, ou seja, tomar os jovens não como objetos, mas como sujeitos. A partir daí fomos unindo e compilando estes estudos e nos damos por conta que todos abarcam os distintos tipos de juventudes existentes na América Latina, segundo diferenças de gênero, classe, geração, etnia, território e ocupação. Daí vem o título de "juvenopédia", uma minienciclopédia em construção, na qual apresentamos diferentes juventudes: jovens masculinos e femininos, operários e estudantes, indígenas e mestiços, rurais e urbanos, e depois as manifestações de culturas juvenis: grafiteiros, "rappers", digitais, em movimento, desqualificadas, esportivas. Obviamente, as categorias eram múltiplas e algumas faltavam, por exemplo, não há estudos neste livro sobre as minorias sexuais, mas se trata de um primeiro mapa e em cada contribuição havia um mapa teórico, um estudo de caso e uma biografia de um jovem concreto, através do qual possamos ver as novas tendências de comportamento das juventudes ibero-americanas em construção. O que há de comum em todas elas? Por uma parte, a trajetória dos estudos em juventudes que é convergente, a qual tem a ver com um contexto político de revoluções por revoluções no neoliberalismo e a tentativa falha de criar um estado de bem-estar na América Latina, o que é comum a quase todos os países, as ditaduras e as tentativas de criar uma democracia mais ou menos participativa. Em segundo lugar, a criação de políticas públicas de juventudes que, a partir dos anos 1980, quase todos os países ibero-americanos, incluindo o Brasil, tentam implementar e que depois de 2005 entram em crise e as cortam. E em terceiro lugar, o protagonismo dos movimentos juvenis nos países pesquisados. Ou seja, as diferenças de culturas, as diferenças políticas, as diferenças históricas e, por exemplo, as diferenças nos níveis de violência, no qual a escola não tem a mesma relevância em todos os países. Sim, há muitos encontros, como 
os movimentos de rede, nos quais os jovens não possuem muitas fronteiras e se conectam entre eles, por exemplo, o capítulo da Juvenopédia sobre os jovens ativistas, em que se demonstra que nas mobilizações de determinado país sempre há jovens de outros países latino-americanos, primeiramente online e depois nas manifestações juvenis, no movimento estudantil presencial, então, as fronteiras acabam se borrando, como na Europa, com o programa "Erasmus" - na América Latina não há este tipo de programa ainda, mas parece que há uma tentativa de criar um programa chamado "Neruda", o qual seria parecido, mas há na consciência coletiva alguma tentativa de criar a América sonhada pelos libertadores, que é uma América sem fronteiras, e oxalá algum dia possa existir.

\section{Entrevistadores: A criatividade das práticas juvenis é um conceito pre-} sente em seus escritos. $O$ senhor poderia explorar mais sobre esta temática, tendo em conta as vivências contemporâneas dos jovens?

Carles Feixa: Meu interesse pela criatividade, talvez porque desde pequeno desenhava e gostava do desenho e da arte, mas também porque minhas primeiras experiências de pesquisa, na Catalunha, na Espanha e no México, encontraram nos jovens uma multicriatividade na música e através de outras produções culturais, como o desenho, o "grafitti", a arte, o cinema e a "cibercultura". Eram dados que contrastavam com as imagens pejorativas dos meios de comunicação do discurso eminente que via o jovem como periférico, mas que os jovens não apenas imitavam, mas também criavam a moda e suas produções também eram relevantes. E nos últimos anos me interessei pela neurociência, e as novas disciplinas neurocientíficas demonstram que o cérebro dos adolescentes ou dos pós-adolescentes está em uma fase de máxima expansão. Há uma fase da vida entre a puberdade e a chamada mielinização, uma fase de expansão cerebral na qual somos potencialmente mais produtivos, visto que o cérebro já está formado, mas possui uma capacidade de estabilização e de criatividade muito elevada. Por casualidade, entre os 15 e 25 anos, nesta fase já há uma experiência, fruto da educação prévia, mas não há uma rigidez vital nem neuronal, com a qual esta capacidade de criar é quase nata, mas nem todos os jovens a desenvolvem, uma vez que a cortam. Portanto, seria uma explicação neurobiológica esta capacidade criativa das culturas juvenis, a qual depende de como a sociedade abre as portas para este canal, um canal aberto numa sociedade repleta de violência e sem instrução que pode se prejudicar a si mesmo e à sociedade. Outras vezes canaliza-se através do consumo e do mercantilismo, isto que as grandes empresas aprenderam a fazer, tendo jovens como cobaias para que lhes digam que produto vai ter êxito. Alguns acabam despontando, como Mark Suckerberg ou outros tecnólogos famosos, mas há essa possibilidade, e é um recurso o qual devemos aproveitar da juventude, se não aproveitarmos nossa 
sociedade está condenada a retroceder e não superar suas próprias contradições. Então é uma das falhas das políticas contemporâneas que temem as juventudes e as reprimem, sem se darem conta de que sem eles esta vontade de mudança e de renovação faz a sociedade como morta. A sociedade contemporânea está em movimento e se param os jovens, vem a crise.

\section{Entrevistadores: Quais instrumentos metodológicos o senhor consi- dera serem importantes para os registros das práticas juvenis?}

Carles Feixa: Desde as minhas primeiras pesquisas, sem pensar muito, eu priorizei uma técnica particular que são as histórias de vida, a qual sempre trabalhei e sigo trabalhando, a converti em meu ponto de vista principal, sem descartar outras metodologias e outras técnicas. Considera-se que a juventude não tem história de vida ou biografia porque ainda estariam em construção, por outro lado, me dei conta de que era justamente o momento em que poderiam começar a narrar e a construir, a partir das perguntas que eu fazia como antropólogo e pesquisador, e também, na origem, como jovem, porque quando eu comecei eu era jovem como aqueles os quais eu entrevistava. Entrevistava pessoas da minha própria idade, alguns companheiros, pessoas queridas ou amigos e amigas. Assim me dei conta de que era uma possibilidade dar-lhes a opção de narrarem-se, a si mesmos, de buscarem o conteúdo de suas identidades. É uma técnica que sigo aplicando e pensando ser clássica em ciências sociais, no caso da juventude segue relevante, posto que permite dar a possibilidade não somente de capturar muita informação vivida, mas sobretudo de personalizar uma narratividade dos próprios jovens, dos próprios sujeitos. Nos últimos anos fui completando, através da participação em projetos europeus e internacionais, já não se tratam apenas de pesquisas individuais, artesanais e pequenas, mas estudos muito mais completos e mais amplos, nos quais não são suficientes poucas histórias de vida, como esta que estamos fazendo agora, mas são necessárias triangulá-las com outras técnicas. Não descarto nenhuma técnica, em função do tema, da possibilidade, uso outras, como a fotografia, tanto do pesquisador quanto dos sujeitos, como um elemento que hoje em dia está muito presente na vida dos jovens contemporâneos através dos celulares, os quais ali põem ao vivo suas visões da vida e do mundo, literalmente. Em segundo lugar, o vídeo, não tanto como uma técnica de registro do que passa aos jovens, mas como uma técnica de participação ativa, na qual eles se apropriam e participam como autores protagonistas, como a pesquisa que acabamos de iniciar sobre jovens em doze cidades do mundo, vamos utilizar uma série de documentários sobre a vida nas "bandas" em doze cidades. E, em terceiro lugar, a chamada etnografia virtual que, em meu caso, a utilizo de uma maneira artesanal, não tanto aplicando programas sofisticados, mas vendo como o ciberespaço é outro espaço 
de observação no qual estão presentes os jovens; segui-los por este espaço é útil. E, para além destas três técnicas, não descarto, em função dos estudos de conjuntura, qualquer tipo de modo de análise que vão desde os grupos focais, a análise do discurso dos meios de comunicação, as entrevistas. Nisso sempre tento metodologicamente ter em conta a juventude, mas não apenas falar com os jovens, mas também com o entorno social dos jovens, que são seus pais e mães, os professores, a polícia, os educadores, os pesquisadores. É necessário levar em conta o contexto no qual estão inseridos, porque, no fundo, a juventude não se estuda estudando somente a juventude, mas, sim, seu contexto midiático, político e social.

Entrevistadores: Com o incremento dos processos migratórios forçados no século XXI, principalmente de jovens da América Central, do Norte da África e do Oriente Médio, para destinos com supostas melhores oportunidades, como o senhor pensa que se dão as novas conexões e os novos pertencimentos aos espaços?

Carles Feixa: De algum modo é difícil sintetizar, visto que são as pesquisas que venho realizando nos últimos doze anos em Barcelona, primeiramente, com jovens latino-americanos, que chegaram a Barcelona (Espanha), desde os anos 2000, com os processos migratórios transnacionais, depois com os jovens do norte da África. Atualmente, com o projeto que começamos há pouco, com estes dois coletivos: latinos e árabes em Barcelona e no Sul da Europa. Estas pesquisas, de alguma forma, entram no terreno das pesquisas clássicas sobre migrações, desapego e adaptação a um novo território, um novo espaço, com a particularidade de que a migração se dá em uma fase da vida que está entre a infância e a juventude, costuma ser a adolescência. Já não são pessoas maiores de idade que emigram tampouco são crianças que não têm nenhuma influência do país de origem, além de que nasceram e viveram seus primeiros anos de vida no lugar de origem; durante a infância e a adolescência, eles e seus pais tomam a decisão de migrar. Supõe-se, portanto, um transnacionalismo igualitário, uma absoluta miscigenação cultural e social neste processo migratório, para o pior e para o melhor. Para o melhor: permite-lhes serem binacionais, bilíngues, biculturais em todos os sentidos, com a capacidade de adaptarem-se no mínimo a duas ou mais culturas. O negativo é que não são de nenhum lugar, ao final acabam crescendo em uma terra de ninguém e sentindo-se um pouco estrangeiros tanto em seu lugar de origem, quando voltam, como em seu lugar de destino. A identidade pessoal e coletiva está sendo construída neste período, como jovens em transição para o mundo adulto - e isso ocorre com qualquer jovem, não apenas com os migrantes -, mas ao mesmo tempo estão se construindo identidades étnicas e culturais em várias culturas. Há uma terceira influência, 
que é o mundo digital/virtual, pois hoje as identidades não são apenas físicas, presenciais, mas também virtuais e, através do ciberespaço, se modificam, se expressam e vivem esta mistura identitária. Esta nova geração migrante é transnacional, é transmidiática, pois leva a cabo as diferentes tecnologias da informação; também é transgeracional, pois é a geração que eu denomino "1.5", pois não é a geração dos filhos dos imigrantes, nem a primeira que migrou, mas a que está no meio das duas gerações. Os discursos otimistas pensavam que os jovens desta geração, quando estivesse adulta, seriam espanhóis, catalães, europeus, assim, não haveria nenhum problema. A realidade, no entanto, nos monstra que se trata de um tema muito mais complexo, como o que ocorreu no verão passado em Barcelona, o famoso caso do atentado terrorista na "Rambla" que paradoxalmente foi protagonizado por jovens de origem norte-africana que estavam perfeitamente integrados na Catalunha; ou seja, falavam catalão, haviam estudado em uma escola catalã, não haviam manifestado nenhum problema visível, mas de repente são captados por um grupo terrorista e participam de um atentado contra seu próprio país de destino. Isso monstra que, de algum modo, está falhando, e, em outros estudos, já se constatou que até a terceira geração segue sentindo-se discriminada. Há um problema de integração complexo, no qual é inevitável caminharmos em direção a culturas multi e transculturais, isso é um processo inevitável no mundo contemporâneo. Há movimentos de recuo identitário de cunho neoconservador que reivindicam que cada um viva em seu mundo e não haja uma mistura. No entanto, deve haver, sem dúvidas, uma mistura cultural, mas devemos ter cuidado para que esta mistura não produza monstros, mas que ocorra de uma maneira equilibrada e permita com que cada qual construa uma identidade, sem sentir-se discriminado pelos outros. Isso vale tanto para a sociedade de acolhida como para a sociedade de destino, para todos os coletivos que convivem num lugar e num momento determinado.

Entrevistadores: Temos juventudes que, a seu modo, ocupam territórios urbanos. Como o senhor percebe que se dá a apropriação do espaço urbano a partir de diferentes recortes sócio-econômico-culturais?

Carles Feixa: Em cada uma das pesquisas das quais eu participei, tais apropriações se dão de maneiras distintas em função do contexto, do tipo de urbanismo e do tipo de conjuntura. Uma experiência que, de quando eu comecei a pesquisar juventude, vinculada aos espaços urbanos, trabalhava muito com os espaços de ócio, que são os lugares de agregação: os bares, as discotecas, a rua, os lugares de agregação na Espanha, nos anos 1980, as "movidas noturnas", e, portanto, o vínculo dos jovens com o espaço urbano passava muito diretamente por suas vivências em lugares de diversão, nos quais podiam se sentir livres, familiarizados com eles mesmos, podiam se sentir vinculados a estes territórios 
próprios que ao mesmo tempo viviam uma revitalização da cidade, ou seja, de lugares marginais, ocultos e clandestinos da cidade, que, pela presença dos jovens, passavam a ser lugares vividos. Isso se supunha que, os jovens da periferia, não iam ao centro da cidade exatamente, mas até lugares marginais dentro do centro, ou seja, estes lugares de diversão não eram lugares centrais, mas lugares um pouco periféricos. Há outro momento, nos anos 1990, quando esta apropriação do território vai até as periferias urbanas. Os governos municipais, por exemplo, na Espanha e na Catalunha, já não viam bem, com bons olhos, que houvesse lugares de diversão no centro, que criem incômodos aos vizinhos e barulho, e começaram a expulsar para as periferias as discotecas e os lugares de diversão e, com isto, a problemática social da juventude, pois a bebedeira e o consumo de drogas causavam outros pequenos tipos de distúrbios que se produziram. Isso teve como efeito uma segregação social urbana da juventude que não podia viver no centro, inclusive porque o centro das cidades era mais caro para se viver, nas grandes cidades o centro era ocupado pela elite financeira e pelo consumo de quantidades econômicas elevadas, mas ao mesmo tempo sentiam-se um pouco excluídos. A fase seguinte, conhecida como o "movimento dos indignados", em 2011, quando há uma volta, uma tentativa de voltar a ocupar o centro. Há um costume chamado "el botellón", com os bares muito caros para consumir, em algumas ruas marginais se juntavam, se reuniam com garrafas de álcool e bebidas gasosas para beber. Havia certa tolerância em relação a estas práticas, mas era como malvisto. Em 2011 há uma volta ao centro, à visibilidade, além de uma tentativa de voltar a serem membros "da periferia do centro", o marginal passa a ser central de algum modo, não ao nível de consumo, mas ao nível político, ou seja, a politização do espaço público. De 2011 aos dias atuais, podemos afirmar que há uma volta à marginalidade, uma expulsão dos jovens do espaço público, há um maior controle em relação ao uso dos espaços, das ruas, dos shoppings, especialmente dos jovens que procedem de setores populares, de bairros periféricos, supõe-se que lhes impõe todas as barreiras possíveis para que não cheguem ao centro, para que não sejam muito visíveis e para que não interfiram com a vida da comunidade. Creio que isso é um grande erro, porque a vida das cidades contemporâneas não é possível sem que os jovens estejam presentes em seu centro histórico, pois é a única maneira de revitalização possível. Um centro de uma cidade sem juventude é um centro morto. Também não destinar tudo aos carros, ao transporte motorizado, quando as cidades, por definição são para caminhar, para viver a pé, cara a cara, que é o que os jovens estão tentando fazer. Acabaria comentando que a revolução a qual estão fazendo os jovens é uma revolução da mobilidade, de inventar e de praticar outras maneiras de viver na cidade, que fujam do transporte privado, do carro, que usem a bicicleta, os patins, o andar; ou seja, usem outras formas 
mais diretas e muito mais sensíveis de habitar a cidade, de reivindicar uma cidade que não seja uma bolha, na qual vai do shopping para a universidade, sem tempo nem espaço para relacionar-se, para caminhar ou para passear. É, no fundo, voltar a reivindicar o passeio, ser um flaneur, que Walter Benjamin e Baudelaire colocavam como exemplo da modernidade: a possibilidade de perder-se na cidade simplesmente para desfrutar da vida na urbe e para relacionar-se com outras pessoas.

\section{Entrevistadores: Quais as recomendações o senhor considera essen- ciais para entrarem na agenda dos "jovens pesquisadores de juventudes"?}

Carles Feixa: Na realidade, creio que a imensa maioria dos pesquisadores das juventudes começou a pesquisa quando jovens, no final de sua etapa juvenil. Eram jovens, mas não adolescentes. Já estavam um pouco amadurecidos e eram ativistas, ou seja, participavam de algum tipo de manifestação juvenil, religiosa, política, social ou esportiva, portanto, se interessavam em estudar e compreenderem-se a si mesmos. No fundo era uma forma de autoanálise, de autoinvestigação. Há algo de autobiografia ou autoetnografia nestas primeiras fases de pesquisa juvenil. Em alguns casos foi algo conjuntural e logo passaram a outros temas, esquecendo-se das juventudes. Em outros casos, nos mantivemos na pesquisa com as juventudes porque quisemos ou porque devido à dinâmica por sorte ou desgraça - não precisa inventar temas de pesquisa em juventudes. Os temas brotam espontaneamente, te atropelam, não é que temos que ir atrás do que pesquisar, mas constantemente estão chegando novos temas, novos sujeitos. E, dos anos 1985 até hoje, desde os tempos das "bandas" juvenis e das tribos, a música eletrônica, a imigração transnacional, as bandas latinas, os indignados, sempre há temas novos que vem surgindo. Eu nunca busquei estes temas, eles sempre vieram me buscar. Portanto, minha recomendação, minha sugestão é que isso vai continuar acontecendo, que os ativistas juvenis de hoje convertam sua paixão e seu ativismo militante ou seu "hobbie" em uma forma de pesquisa mais profissional, mais séria, mas que ao mesmo tempo não percam nunca esta capacidade de emocionarem-se e de comprometerem-se com este tema de pesquisa. Que não deixe nunca de ser um tema neutro, pois poderiam estudar as juventudes ou qualquer outro tema, mas que lhes mova sempre um vínculo pessoal e emocional de interesse, de vinculação direta que, no fundo, é o secreto elixir da eterna juventude, a capacidade de renovar os pensamentos através da criatividade, das informações e das renovações que vem do mundo juvenil. A chave é que não há uma "gerontrocatização" da pesquisa em juventudes. É verdade que houve, desde os primeiros investigadores, uma, duas ou três gerações de pesquisadores em juventudes: a nossa, com José Machado Pais e a que veio depois; ou seja, outras gerações sempre foram crescendo e sempre 
houve uma necessidade de renovar-se, de que viessem novas gerações. Fato que em algum momento, na Espanha, foi complicado, visto que havia uma fratura na universidade que impedia que pudessem vir novos acadêmicos, assim, as novas gerações tiveram mais dificuldades em inserção na vida acadêmica. Por isso é chave que a pesquisa em juventudes não se converta em uma pesquisa de velhos que analisa a juventude, nem apenas de jovens que se estudam, mas que haja um diálogo intergeracional, uma interação que enriqueça mutuamente, posto que nós possamos ancorar com ideias, teorias e fatos de outros momentos da pesquisa em juventudes. Vocês trazem as novidades, aquilo que está surgindo, aquilo que ainda não temos claro, pois vocês o vivem. Nós vemos um pouco de fora, mesmo que tenhamos filhos e alunos que nos fazem viver tudo outra vez. O antropólogo sempre estuda os outros, mas nunca deixa de estudar-se a si mesmo, e isto é a chave.

\section{PUBLICAÇÕES DO AUTOR (SELEÇÃO)}

FEIXA PAMPOLS, C. De jovenes, bandas y tribus. Barcelona: Ariel, 1998.

FEIXA PAMPOLS, C. Geración@: la juventud al siglo XXI. Barcelona: Aportación $12,2002$.

FEIXA PAMPOLS, C.; CACCIA-BAVA, A.; CANGAS, Y. G. (Orgs.). Jovens na América Latina. São Paulo: Escrituras, 2004.

FEIXA PAMPOLS, C.; FERRÁNDIZ, F. Jóvenes sin tregua: culturas y políticas de la violencia. Barcelona: Anthropos, 2005.

FEIXA PAMPOLS, C. \#GeneraciónIndignada: Topías y utopías del 15M. Barcelona: Editorial Milênio, 2013.

FEIXA PAMPOLS, C. De la Generación@ a la \#Generación. Barcelona: Ned Ediciones, 2014.

FEIXA PAMPOLS, C.; OLIART, P. Juvenopedia: Mapeo de las juventudes latinoamericanas. Barcelona: Ned Ediciones, 2016.

Texto recebido em 27 de fevereiro de 2018.

Texto aprovado em 13 de março de 2018. 
